\title{
Teaching best-evidence: Deltoid intramuscular injection technique
}

\author{
Kathleen Marie Davidson ${ }^{1}$, Liam Rourke ${ }^{2}$ \\ 1. Faculty of Nursing, University of Calgary, Canada. 2. Department of Medicine, University of Alberta, Canada \\ Correspondence: Kathleen Marie Davidson. Address: Faculty of Nursing, University of Calgary, Canada. Email: \\ kmdavid@ucalgary.ca.
}

Received: October 22, 2012

Accepted: November 7, 2012

Online Published: January 17, 2013

DOI : $10.5430 /$ jnep.v3n7p120

URL: http://dx.doi.org/10.5430/jnep.v3n7p120

\section{Abstract}

Intramuscular injection of vaccines and medications into the deltoid muscle is a long-established nursing practice. The deltoid muscle is the preferred site for intramuscular injections to adult clients in community settings, as it requires minimal, generally socially-acceptable, exposure of the client's body, and is easily accessible to the professional administering the injection. Nursing students learning to administer deltoid intramuscular injections raise excellent questions about deltoid intramuscular injection technique, in particular around landmarking technique, the use of bunching or flattening technique, and selection of needle length. Surprisingly little empirical evidence to guide the nurse, or to answer student questions about, administering deltoid intramuscular injections was found in the nursing and allied health literature. This article examines deltoid intramuscular injection practice with particular emphasis on teaching nursing students best practice.

\section{Key words}

Nursing, Education, Deltoid, Intramuscular injection

\section{I ntroduction}

In Canada, Fall is influenza immunization season. Each year, beginning in October and running until December, dedicated efforts are made to encourage everyone who lives, works or goes to school in Canada to have an influenza immunization. To this end, public immunization clinics, offering free influenza immunizations, are set up in large and small communities. Student nurses, after being taught the knowledge and skills necessary for administering influenza vaccine, participate as vaccinators in the public influenza clinics. As each generation of nursing students participates in the influenza immunization clinics, they ask the same excellent questions about deltoid intramuscular injection (IMI), which tend to fall into three themes: 1) landmarking technique, 2) bunching or flattening technique, 3) selection of needle length.

Until the late 1940s, intramuscular injections were exclusively within physician scope of practice; the role of the nurse was to prepare the equipment and the patient, and to assist the physician ${ }^{[1,2]}$. Intramuscular injections for children, given by the nurse, were described in The American Journal of Nursing in $1948^{[3]}$. By 1964, nurses were administering most intramuscular medications, and Pitel and Wemett were among the first authors to provide detailed instructions for nurses on anatomic sites, including the deltoid, for intramuscular medication administration, landmarking of the sites, and injection technique ${ }^{[4]}$. 
Deltoid intramuscular injection requires "penetration of the needle into the deltoid muscle layer by $5 \mathrm{~mm}$ or more to ensure that the injection would be into the muscle mass" (p. 1710) ${ }^{[5]}$. The inadvertent injection of vaccine into the subcutaneous tissue, instead of into the muscle, results in more serious local reactions and compromised immunogenicity ${ }^{[6-10]}$. As well, injury to the axillary nerve following deltoid IM injection has been reported in the literature ${ }^{[11,12]}$. Abscesses and granulomas, although rare, can occur when vaccine or medication intended for intramuscular injection is inadvertently delivered into subcutaneous tissue ${ }^{[5]}$. Safely delivering vaccine or medication into the deltoid muscle is not a trivial matter, and nursing students need to be equipped with best evidence to ensure safe, client-centered practice when administering vaccine or medications via the deltoid IMI route.

Deltoid IMI is a procedure which nurses around the world perform millions of times a year, yet surprisingly little empirical evidence exists in the nursing and allied health literature to guide the nurse or to inform the teaching of nursing students. Only 40 relevant articles, both research $(n=13)$ and theoretical/discussion papers $(n=27)$ were found in a thorough search of the literature using the search terms injection methods, immunization, intramuscular injection, intramuscular injection technique, deltoid, deltoid injection, deltoid intramuscular injection. The search was conducted using the databases Cumulative Index to Nursing and Allied Health Literature (CINAHL), MEDLine, PubMed, and ProQuest Dissertations and Theses. As well, specific journals with very long publication histories (American Journal of Nursing, British Medical Journal) were searched back to their first publication dates. Publishing house search engines, which index all journals with a common publisher, such as Academic OneFile and Sage Publications, were searched from 1847 to the present. As well, five nursing fundamentals textbooks, dating back to 1945, were reviewed regarding deltoid IMI instructions and supporting literature. Relevant publications from government and non-governmental agencies, such as Center for Disease Control (CDC) Morbidity and Mortality Weekly Report (General Recommendations on Immunization), World Health Organization (Immunization in Practice), American Academy of Pediatrics (Report of the Committee on Infectious Diseases), and Public Health Agency of Canada (Canadian Immunization Guide) were also reviewed. The evidence provided by the literature to address common themes of student questions (landmarking technique, bunching or flattening technique, issues influencing required needle length) is briefly summarized below.

\subsection{Landmarking techniques}

A landmark is defined as "an anatomical structure used as a point of orientation in locating other structures (as in surgical procedures)" ${ }^{[13]}$. Student nurses are taught to use landmarks when giving intramuscular injections, in order to avoid injuring adjacent structures. Landmarking techniques for the deltoid site (three finger breadths below the acromion or/and axillary triangle method) are described by early nursing authors ${ }^{[4,14]}$. For deltoid intramuscular injections, contemporary student nurses are generally taught to palpate the acromion process, then place 3 fingers across the deltoid muscle directly below the acromion ${ }^{[15]}$. Some nursing textbooks suggest that the student nurse should use four fingers, placing the little finger on the acromion process, and three fingers below ${ }^{[16]}$, while other authors recommend "two-to-three fingerbreadths below the acromion process" (p. 62) ${ }^{[17]}$.

The nursing literature does present a consensus opinion that deltoid IMI should be given 2.5 to $5 \mathrm{~cm}$ below the acromion process. However, a review of the anatomy of the deltoid muscle and axillary nerve demonstrated that the axillary nerve is generally located $5-7 \mathrm{~cm}$ below the tip of the acromion, but the distance ranges between $4.34 \mathrm{~cm}$ and $6.39 \mathrm{~cm}$, with an average distance of $5.58 \mathrm{~cm}^{[18]}$. Therefore, a nurse who administers a deltoid IMI $5 \mathrm{~cm}$ below the acromion may be mere millimeters away from the axillary nerve. If a nursing student has large hands, landmarking with three fingerbreadths below the acromion could easily place the injection $5 \mathrm{~cm}$ or more below the acromion, illustrating the pitfalls of relying on traditional, ritualistic practices.

As noted above, student nurses are taught to use landmarks when giving intramuscular injections, in order to avoid injuring adjacent structures. However, are nursing students taught exactly what at risk structures and where those structures are located? McGarvey and Hooper found that knowledge of the at-risk structures (axillary nerve, subdeltoid bursa, circumflex humeral arteries) was poor among both practicing nurses and physicians; half of those surveyed could not 
name any structures at risk ${ }^{[19]}$. McGarvey and Hooper further note that the subdeltoid bursa may extend $5 \mathrm{~cm}$ below the acromion process; these authors recommend deltoid IMI should be given "at or below the midpoint of the muscle" (p. 107).

\subsection{Bunching or flattening techniques}

"Bunching" technique is when the nurse pinches, or squeezes, the deltoid muscle between the non-dominant thumb and forefinger before injection to increase muscle mass and minimize the chance of striking bone ${ }^{[8,20]}$. "Flattening" technique is when the nurse spreads, or stretches, the skin overlying the deltoid muscle between his/her non-dominant thumb and forefinger before injection to compress subcutaneous tissue and increase the likelihood of injecting into muscle mass ${ }^{[8]}$. Whether the nurse chooses bunching or flattening technique, the required needle length and likelihood of achieving IMI may be affected.

Contemporary nursing textbooks continue to instruct nursing students to stretch the skin of adult clients taut between thumb and forefinger before inserting the needle ${ }^{[15,16,21,22]}$. One group of textbook authors are alone in instructing their readers to stretch the skin taut prior to intramuscular injection but "grasp the skin in pediatric and geriatric clients" (p. 310), but these authors provide no further direction ${ }^{[22]}$. It must be noted that these ubiquitous instructions for intramuscular injection in nursing fundamentals textbooks cite no empirical evidence to support the use of these techniques.

Some sources note that bunching technique is more common in the United States, while other sources note the flattening technique is recommended by the World Health Organization ${ }^{[8,20]}$. However, neither of these techniques could be definitively linked to either the Centers for Disease Control and Prevention (CDC) "General Recommendations on Immunization" nor to the World Health Organization (WHO) "Immunization in Practice Guide" ${ }^{[23-25]}$. In fact, the WHO immunization guide (2004) recommends flattening technique for intramuscular injections into the thigh for infants under 15 months of age, and bunching technique for deltoid injections in clients over 15 months ${ }^{[25]}$. This WHO recommendation is supported by one study which determined that with infants and toddlers, if a 1-inch (25mm) needle is being used, bunching technique is appropriate; if flattening technique is used in this very young population, and 5/8 inch (16mm) needle is appropriate ${ }^{[26]}$. In another study of the toddler population, Cook and Murtagh concurred, noting that when using the flattening technique, a shorter needle is required because underlying tissues are compressed ${ }^{[20]}$. However, in a study with an adolescent population, bunching or flattening technique did not result in a change to the appropriate needle length required to achieve $\mathrm{IMI}^{[8]}$.

The use of bunching or flattening technique significantly affects the deltoid fat pad and skin-to-muscle distance, and therefore, the required needle length ${ }^{[8]}$. Cook, Williamson and Pond studied the deltoid muscle and fat pad in older adults, and found that females with the same body mass index as males had significantly thicker deltoid fat pad, and a thinner deltoid muscle layer ${ }^{[27]}$. Since it is the skin and subcutaneous layers which are significantly raised with bunching technique, bunching technique with older adults may result in inadvertent subcutaneous injections, particularly in females with body mass index greater than 35 .

\subsection{Needle length}

The literature provides strong research-based evidence to guide the selection of needle length for deltoid IMI. Three randomized controlled trials were found which investigated needle length, and another seven studies were found which employed quasi-experimental designs to investigate needle length. Using ultrasound to determine deltoid fat pad thickness, a 1997 benchmark study provides definitive guidelines for selecting needle length based on the client's weight ${ }^{[5]}$. This 1997 study found that for men $60-118 \mathrm{~kg}$, a one-inch $(25 \mathrm{~mm})$ needle consistently achieves IMI. However, the results were considerably more variable for women: for women weighing less than $60 \mathrm{~kg}$, a $5 / 8$ ” $(16 \mathrm{~mm})$ needle would be sufficient to achieve IMI. Women weighing between $60-90 \mathrm{~kg}$ required a one-inch $(25 \mathrm{~mm})$ needle, and for women over $90 \mathrm{~kg}$, a 1.5 inch (32mm) needle would be required to achieve IMI. Moreover, in clients over age 65, the deltoid muscle 
atrophies while the deltoid fat pad thickens, meaning the longer needle is more necessary for the older client, not the young client with muscular arms.

Center for Disease Control (CDC) guidelines direct health practitioners to select needle length for IMI based on the body weight in adult clients ${ }^{[23]}$. In Canada, the National Advisory Committee on Immunization provides a general recommenddation to base selection of needle length on the client's size and age, as well as on the muscle mass being injected and viscosity of the injectate, with the further recommendation that a 22-25 gauge, one inch $(25 \mathrm{~mm})$ needle for infants, toddlers and older children, and a 22-25 gauge, one to one-and-a-half inch needle for adolescents and adults ${ }^{\text {[28] }}$. Unfortunately, unlike the CDC guidelines, the Canadian guidelines provide no specific direction to the health care professional for selecting the appropriate needle length. A related question is whether the needle should be fully inserted to the hub, or if a few millimetres should be left outside the skin. Hunter advocates that nurses "insert the needle at a 90degree angle until approximately $1 \mathrm{~cm}$ of the needle is left showing” (p. 38) ${ }^{[29]}$. Hunter's recommendation flies in the face of the evidence: a one-inch $(25 \mathrm{~mm}$ ) needle left $1 \mathrm{~cm}$ out of the skin delivers the injection at a depth of $15 \mathrm{~mm}$, even less than the penetration achieved by a 5/8" (16mm) needle, and certainly inadequate depth for all adult male clients, and all adult female clients weighing more than $60 \mathrm{~kg}$.

\subsection{I mmunogenicity and reactogenicity}

Several articles in the literature address the question of needle length, with respect to immunogenicity and reactogenicity. If needle length is inadequate, the injected vaccine or medication will be deposited into subcutaneous tissue. Several studies over the past 20 years have demonstrated that immune response to vaccine (immunogenicity) is best achieved, and local reaction (reactogenicity) is minimized, when the vaccine is injected into muscle rather than into subcutaneous tissue $^{[9,26,30]}$. Immunogenicity and reactogenicity are not trivial matters, particularly in the context of a thriving and powerful anti-vaccination movement ${ }^{[31,32]}$. Anti-vaccine groups host thousands of social networking pages and internet websites which promote anecdotal claims that vaccines are ineffective and cause severe mental and physical health consequences ${ }^{[31]}$. In the absence of immediate infectious disease threat, the lay public regards all vaccine information on the internet and social networking sites as equally credible, regardless of the source ${ }^{[32]}$. Nurses in clinical practice frequently hear clients report that "I got the flu shot and still got the flu", or "my arm was so sore last year after the flu shot that I'll never get another one”. Even worse, nurses themselves are often guilty of spreading anti-vaccine anecdotes; only about $46 \%$ of Canadian health care workers get an influenza immunization every year ${ }^{[33]}$. Reasons given by nurses for not getting the influenza vaccination include the belief that the vaccine itself causes influenza, or that it is ineffective and/or unproven, or that they (the nurse) "have never taken a flu shot and have never had the flu" ${ }^{[34]}$. Such stories 'fan the flames' of the anti-vaccination movement. Clinical decision-making and injection technique by the nurse at the point of care, which ensures that vaccine is deposited into muscle tissue and not into subcutaneous tissue, maximizes immune response while minimizing local reaction, and avoids contributing to the anti-vaccination movement.

\subsection{Obesity epidemic}

The question of needle length is also increasingly salient with the rising prevalence of overweight and obesity in the developed world. Subcutaneous tissue thickness is increased in obese individuals, and a longer needle length may be required ${ }^{[9]}$. In Canada, the prevalence of overweight and obesity (BMI $>25 \mathrm{~kg} / \mathrm{m}^{2}$ ) among males aged 15 years and older is $66.9 \%$, and among Canadian women is $59.5 \%{ }^{[35]}$. Body weight can be used to accurately predict the required needle length for deltoid immunization of healthy adolescents and adults ${ }^{[5,8]}$. The obesity epidemic surely lends greater importance to selecting needle length for IMI based on the client's body weight.

\subsection{Overpenetration}

Lippert and Wall examined needle overpenetration through the muscle and into the bone or periosteum in children 2 months to 18 years old ${ }^{[36]}$. These authors determined that overpenetration of the deltoid muscle was a risk when immunizing children, and that needle length be selected according to the weight of the child. No similar study of needle 
overpenetration in adults was found. However, case reports of injury to the axillary nerve following overpenetration of deltoid IM injection are reported in the literature ${ }^{[11,12]}$.

\subsection{Needle aspiration}

Whether or not to teach students to perform needle aspiration when administering IM injections is a questions frequently asked by nursing practice instructors. Needle aspiration is performed by pulling back on the plunger of the syringe after inserting the needle into the client; if blood appears in the syringe, the nurse assumes the needle is in a blood vessel, and withdraws the needle prior to injection. There is no scientific evidence to support the need for aspiration ${ }^{[37]}$, and several evidence-based reasons not to perform aspiration. First, the sites used for intramuscular injection are not in close proximity large blood vessels ${ }^{[38]}$, so the likelihood of inadvertently hitting a blood vessel is slight. Second, for needle aspiration to be effective, it must be sustained for at least 5-10 seconds, which is far longer than the quick 1-2 second aspiration generally performed by nurses and other health professionals. One study notes that only $3 \%$ of vaccinators aspirated for the recommended 5-10 seconds ${ }^{[37]}$. Third, rapid injection without aspiration was less painful for the client, likely because aspiration, when performed properly for 5-10 seconds, results in longer contact time between the needle and the tissue and inevitable movement of the needle within the tissue during aspiration ${ }^{[38,39]}$. Finally, "bleeding at the injection site is common, and does not indicate incorrect injection technique" (p. S68) ${ }^{[39]}$. Therefore, needle aspiration should not be performed because it is unnecessary and increases pain at the injection site.

\section{Case presentation}

In the influenza immunization clinics, as with all clinical practice settings, student nurses are perplexed by their observation of wide variations in the performance of nursing skills. The following three vignettes illustrate clinical practice dilemmas encountered by student nurses.

A student nurse is observing a Registered Nurse (RN) in the influenza immunization clinic. He observes that the RN does not manually landmark, but rather seems to 'eyeball' the injection site. The student nurse asks the RN how she landmarks for deltoid intramuscular injection. The RN tells the student that she uses experience to choose the injection site "at the point of the muscle, a bit below the axilla", but invites the student to demonstrate what he has been taught about deltoid IMI landmarking with the next client. The next client is a 30 year-old man with muscular arms. The student confidently palpates the acromion process, places three fingers below the acromion, determines the midline of the deltoid muscle, and indicates to the RN that he would aim the injection at that spot. The RN vigorously corrects the student, telling him that his selected site is "much too high", and that he should be "very concerned about giving an injection that high - better to aim low". The student returns to his clinical instructor, full of questions about what he was taught at the university. The nursing student asks his nursing practice instructor, "How can three fingers below the acromion process work as a deltoid injection landmark for every nurse, when my classmate’s fingers are much bigger/smaller than mine”? Shouldn’t we be doing what the experienced nurses are doing, and aiming much lower?”

A second student nurse is observing a Registered Nurse in the influenza immunization clinic. The student observes that the RN uses a one-inch $(25 \mathrm{~mm})$ needle for deltoid IMI with every client, large and small. The student notes that 1.5 inch (32 $\mathrm{mm}$ ) needles are available, but the RN never uses the longer needle. The student nurse asks the RN about selecting the correct needle length for clients of different sizes. The RN tells the student, “If a client is small or elderly, I don't insert the whole needle into the skin - I leave a few millimetres out. For everybody else, a one-inch needle is long enough. You definitely don't want to hit bone - that's the worst thing you can do! You would probably hit bone every time with a 1.5 inch needle”. Once again, the perplexed student questions her nursing practice instructor: "How can a one-inch (25mm) needle be correct for every client, when a 20 year-old male client has muscular arms which are twice the size of the arms of an 80 year-old female client? And, we had a client who was obese, and the RN still used a one-inch needle.” 
A third student is observing the RN in the same influenza immunization clinic. The student asks the RN, "Why do you bunch the skin prior to intramuscular injections, while clinical instructors tell us to stretch the skin taut prior to giving the injection"? The RN explains to the student that bunching raises the muscle, to ensure the vaccine is delivered intramuscularly. The RN goes on to explain to the student that stretching the skin taut increases the risk of hitting bone. This explanation is opposite to what the student has been taught in the clinical simulation laboratory at the university.

In post-conference at the end of the clinical shift, the nursing students are perplexed, and express their dismay about the discrepancies between the IMI practices they have observed the RNs using, and what they have been taught. The students badly want to emulate the RNs so they fit in with the nursing culture of the influenza clinic, and ask their nursing practice instructor if they can "give injections the same way the experienced RNs do".

\section{Discussion}

Almost 20 years ago, Lee, Lee and Eldridge noted that nurses relied on tradition and "ritualistic practice" when administering IMI, and the rationales given by nurses for their IMI technique lacked scientific base (p. 32 ) ${ }^{[3]}$. This unfortunate observation remains valid today; a wide discrepancy persists between research and nursing practice with respect to IMI, a gap which is perplexing to nursing students and novice nurses ${ }^{[2,38]}$. Empirical evidence exists to inform some aspects of administering deltoid intramuscular injections, but certainly not all.

Anecdotally, nurses are most afraid of striking bone when administering IMI. Wilkoff describes striking bone as "a

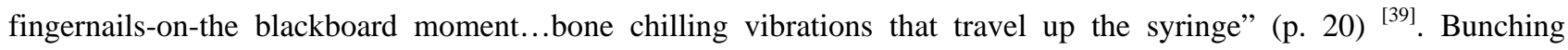
technique, universal use of 1.0-inch (25mm) needles, and leaving a few millimetres of the needle outside the skin if a client appears to be thin, are all common strategies used by nurses to avoid hitting bone. However, in over-emphasizing the avoidance of hitting bone, nurses have overlooked the potential for damage to other structures with deltoid IMI, particularly the axillary nerve.

The nursing and allied health literature is silent on the question of bunching versus flattening technique for deltoid IMI. The literature reveals surprisingly little evidence to support one clinical technique (bunching or flattening) over another. However, since bunching technique is used by nurses primarily to avoid hitting bone, this fear should be ameliorated by having nurses select needle length based on the client's body weight. Nursing students, and practicing nurses, should be taught that the use of bunching or flattening technique significantly affects the deltoid fat pad and skin-to-muscle distance, and therefore, the required needle length ${ }^{[8]}$. Since it is the skin and subcutaneous layers which are significantly raised with bunching technique, bunching technique with older adults may result in inadvertent subcutaneous injections, particularly in females with body mass index greater than $35^{[27]}$.

The evidence is clear that needle length for IMI should be based on the client's body weight. Disturbingly, although this evidence has been available for some 15 years ${ }^{[5]}$, it does not yet inform nursing practice, nor has it been incorporated into nursing fundamentals textbooks. It is not common practice for nurses to directly assess, or even to inquire about, body weight in order to make a decision about required needle length. The days of 'one-inch needles for everybody' should be long past: needle length for deltoid IMI should be selected as follows: for male adult clients between 60-118kg (130-260 lbs), a one-inch $(25 \mathrm{~mm})$ needle is sufficient. For women weighing less than $60 \mathrm{~kg}$ (130lbs), a $5 / 8$ inch (16mm) needle is recommended. Women between $60-90 \mathrm{~kg}(130-200 \mathrm{lbs})$ require a one inch $(25 \mathrm{~mm})$ needle. Women above $90 \mathrm{~kg}(200 \mathrm{lbs})$ and men above $118 \mathrm{~kg}$ (260lbs) require a $1.5 \mathrm{inch}(32 \mathrm{~mm})$ needle to achieve IMI ${ }^{[23]}$. In the Canadian province of Alberta, immunizing nurses have access to both one inch $(25 \mathrm{~mm})$ and 1.5 inch $(32 \mathrm{~mm}), 25$ gauge needles, to use at their discretion

“depending on muscle mass and adipose tissue” (p. 18) ${ }^{[40]}$. Nursing discretion should be based on clear, evidence-based guidelines for selecting needle length by client body weight. 
Although the literature on deltoid landmarking is not robust, seminal work on deltoid anatomy ${ }^{[11,41]}$ coupled with McGarvey and Hooper's survey demonstrating that a majority health care professionals administering deltoid IMI lack knowledge of the underlying structures at risk ${ }^{[19]}$, should lead nurse educators to revise what nursing students are taught about landmarking for deltoid IMI. First, nursing students should be required to thoroughly review the structures at risk beneath each intramuscular injection site, and the potential injuries clients may incur if those structures are damaged during IMI. Second, the assumption that "three fingers below the acromion process" as a universal deltoid IMI landmarking method is accurate for all nurses, should be retired. When those instructions first appeared, in nursing fundamentals textbooks of the 1950s, North American nurses were a homogenous group of young, Caucasian women. However, the nursing workforce is no longer homogenous, and it can no longer be assumed that every nurse has similar fingers. Therefore, nursing students should measure their own fingers, and determine how many fingers that specific student should place below the acromion to ensure safe landmarking of a deltoid IMI. Four centimetres below the acromion should be the target zone for deltoid IMI to ensure the safety of the axillary nerve; giving an IMI $5 \mathrm{~cm}$ below the acromion places the injection too close to the axillary nerve in the event of overpenetration ${ }^{[11,41]}$.

Finally, all nursing students should be taught about the adverse consequences, in terms of decreased immunogenicity and increased localized reaction, of administering vaccine into subcutaneous tissue ${ }^{[9,26,30]}$. Nurses in clinical practice frequently hear clients report that "I got the flu shot and still got the flu", or "my arm was so sore last year after the flu shot that I'll never get another one". Such stories fan the flames of the anti-vaccination movement, and one wonders how many of these stories arise from the inadvertent administration of influenza vaccine subcutaneously, rather than intramuscularly. Clinical decision-making and injection technique by the nurse at the point of care, which ensures that vaccine is deposited into muscle tissue and not into subcutaneous tissue, maximizes immune response while minimizing local reaction, and avoids contributing to the anti-vaccination movement. As nurse educators, we have a role in ensuring that student nurses are combating the anti-vaccine movement with excellent, and evidence-based, IMI knowledge, skills and abilities.

\section{Conclusion}

What should nursing clinical instructors teach as best practice for deltoid intramuscular injection in adults? Three bestpractice changes should be implemented immediately in nursing education programs: First, student nurses should be taught the structures at risk with intramuscular injection. It is not sufficient to teach students that 'hitting bone' is the only adverse consequence. Second, the student nurse should measure his/her own fingers to determine a $4 \mathrm{~cm}$ span to be used for landmarking of the deltoid site. Third, student nurses should be taught to select needle length based on the client's body weight.

As with any practice change, having strong evidence to support specific IMI techniques does not mean change will be readily incorporated and maintained. While it is seemingly easy to ensure that upcoming generations of student nurses are taught IMI techniques which incorporate best evidence, their clinical instructors are practicing nurses, who are likely challenged by, and may be skeptical of, new evidence. Nurses tend to use personal motives to choose whether or not to incorporate a new best practice technique ${ }^{[42]}$. Carter-Templeton and McCoy note that while nurses should base their practice on research, "many nurses use ritualistic practice....and feel more comfortable asking colleagues for information rather than seek[ing] evidence-based resources themselves” (p. 239) ${ }^{[38]}$. Before student nurses are taught best evidence for IMI, it seems prudent to ensure that nursing clinical instructors have replaced their personal IMI rituals and traditions with evidence-based knowledge, skills and abilities. Nursing students ask excellent questions about IMI techniques: we must ensure that their instructors have equally excellent answers.

\section{References}

[1] Harmer, B., \& Henderson, V. Textbook of the principles and practice of nursing. Toronto: MacMillan, 1945. 
[2] Nicoll, L. H., \& Hesby, A. Intramuscular injection: an integrative research review and guideline for evidence-based practice. Appl Nurs Res. 2002; 15(3): 149-162. PMid:12173166 http://dx.doi.org/10.1053/apnr.2002.34142

[3] Wallinger, E. M. Intramuscular injections for children. Am J Nurs. 1948; 48(2): 112. PMid:18904555

[4] Pitel, M., \& Wemett, M. The Intramuscular Injection. Am J Nurs. 1964; 64: 104-109. PMid:14140640 http://dx.doi.org/10.2307/3419063

[5] Poland, G. A., Borrud, A., Jacobson, R. M., McDermott, K., Wollan, P. C., et al. Determination of deltoid fat pad thickness. Implications for needle length in adult immunization. JAMA. 1997; 277(21): 1709-1711. PMid:9169899 http://dx.doi.org/10.1001/jama.1997.03540450065037

[6] Jackson, L. A., Neuzil, K. M., Nahm, M. H., Whitney, C. G., Yu, O., Nelson, J. C. et al. Immunogenicity of varying dosages of 7-valent pneumococcal polysaccharide-protein conjugate vaccine in seniors previously vaccinated with 23-valent pneumococcal polysaccharide vaccine. Vaccine. 2007; 25(20): 4029-4037. PMid:17391816 http://dx.doi.org/10.1016/j.vaccine.2007.02.062

[7] Jackson, L. A., Starkovich, P., Dunstan, M., Yu, O., Nelson, J., Dunn, J. et al. Prospective assessment of the effect of needle length and injection site on the risk of local reactions to the fifth diphtheria-tetanus-acellular pertussis vaccination. [Research Support, Non-U.S. Gov't]. Pediatrics. 2008; 121(3): e646-652. PMid:18310184 http://dx.doi.org/10.1542/peds.2007-1653

[8] Koster, M. P., Stellato, N., Kohn, N., \& Rubin, L. G. Needle length for immunization of early adolescents as determined by ultrasound. Pediatrics. 2009; 124(2): 667-672. PMid:19651584 http://dx.doi.org/10.1542/peds.2008-1127

[9] Middleman, A. B., Anding, R., \& Tung, C. Effect of needle length when immunizing obese adolescents with hepatitis B vaccine. Pediatrics. 2010; 125(3): e508-512. PMid:20142295 http://dx.doi.org/10.1542/peds.2009-1592

[10] Petousis-Harris, H. Vaccine injection technique and reactogenicity—evidence for practice. Vaccine. 2008; 26(50): 6299-6304. PMid:18804137 http://dx.doi.org/10.1016/j.vaccine.2008.08.052

[11] Choi, H. R., Kondo, S., Mishima, S., Shimizu, T., Hasegawa, Y., Ida, K., et al. Axillary nerve injury caused by intradeltoid muscular injection: a case report. J Shoulder Elbow Surg. 2001; 10(5): 493-495. PMid:11641710 http://dx.doi.org/10.1067/mse.2001.114682

[12] Davidson, L. T., Carter, G. T., Kilmer, D. D., \& Han, J. J. Iatrogenic axillary neuropathy after intramuscular injection of the deltoid muscle. Am J Phys Med Rehabil. 2007; 86(6): 507-511. PMid:17515691 http://dx.doi.org/10.1097/PHM.0b013e31805b7bcf

[13] http://www.merriam-webster.com/medlineplus/landmark. (10 October 2012, date last accessed).

[14] Dison, N. An atlas of nursing techniques. St. Louis,: C.V. Mosby, 1967.

[15] Ross-Kerr, J. C., \& Wood, M.J. (Potter \& Perry Canadian Fundamentals of Nursing (4th ed.). Toronto: Elsevier-Mosby, 2010.

[16] Kozier, B., Erb, G., Berman, A., Snyder, S.J., Raffin-Bouchal, D.S., Hirst, S., et al. Fundamentals of Canadian Nursing: Concepts, Process \& Practice (2nd Canadian ed.). Toronto: Pearson Canada, 2010.

[17] Hunt, C.W. Which site is best for an I.M. injection? Nursing. 2008; 38: 62. PMid:18989215

[18] Apaydin, N., Tubbs, R. S., Loukas, M., \& Duparc, F. Review of the surgical anatomy of the axillary nerve and the anatomic basis of its iatrogenic and traumatic injury. Surg Radiol Anat. 2010; 32(3): 193-201. PMid:19916067 http://dx.doi.org/10.1007/s00276-009-0594-8

[19] McGarvey, M. A., \& Hooper, A. C. The deltoid intramuscular injection site in the adult. Current practice among general practitioners and practice nurses. Ir Med J. 2005; 98(4): 105-107. PMid:15938552

[20] Cook, I. F., \& Murtagh, J. Optimal technique for intramuscular injection of infants and toddlers: a randomised trial. Med J Aust. 2005; 183(2): 60-63. PMid:16022607

[21] Craven, R. F., \& Hirnle, C. J. Fundamentals of nursing: human health and function (4th ed.). Philadelphia: Lippincott Williams \& Wilkins, 2003.

[22] Hogan, M. A., Bolten, S., Ricci, M.J., \& Taliaferro, D. Nursing fundamentals: Reviews and rationales (2nd ed.). New Jersey: Pearson Prentice Hall, 2008.

[23] Center for Disease Control and Prevention. Recommendations of the Advisory Committee on Immunization Practices (ACIP). MMWR 60 (No. RR02). 2011: 1- 60.

[24] World Health Organization. Immunization in practice: A guide for health workers who give vaccines. Oxford: Oxford University Press, 1989.

[25] World Health Organization. Immunization in practice: A practical guide for health staff. Geneva: WHO, 2004.

[26] Groswasser, J., Kahn, A., Bouche, B., Hanquinet, S., Perlmuter, N., \& Hessel, L. Needle length and injection technique for efficient intramuscular vaccine delivery in infants and children evaluated through an ultrasonographic determination of subcutaneous and muscle layer thickness. Pediatrics. 1997; 100(3 Pt 1): 400-403. PMid:9282716 http://dx.doi.org/10.1542/peds.100.3.400

[27] Cook, IF, Williamson, M., \& Pond, D. Definition of needle length required for intramuscular deltoid injection in elderly adutls: an ultrasonographic study. Vaccine. 2006; 24: 937-940. PMid:16191454 http://dx.doi.org/10.1016/j.vaccine.2005.08.098 
[28] National Advisory Committee on Immunization. Canadian immunizations guide (7th ed). Ottawa, ON: Public Health Agency of Canada, 2006. Available from: http://www.phac-aspc.gc.ca/publicat/cig-gci/p01-07-eng.php (10 October 2012, date last accessed).

[29] Hunter, J. Intramuscular injection techniques. Nursing Standard. 2008; 22: 35-40.

[30] Ipp, M. M., Gold, R., Goldbach, M., Maresky, D. C., Saunders, N., Greenberg, S., et al. Adverse reactions to diphtheria, tetanus, pertussis-polio vaccination at 18 months of age: effect of injection site and needle length. Pediatrics. 1989; 83(5): 679-682. PMid:2717284

[31] Behrmann, J. The anti-vaccination movement and resistance to allergen-immunotherapy: a guide for clinical allergists. Allergy Asthma Clin Immunol. 2010; 6(1): 26. PMid:20843332 http://dx.doi.org/10.1186/1710-1492-6-26

[32] Poland, G. A., Ovsyannikova, I. G., \& Jacobson, R. M. Adversomics: the emerging field of vaccine adverse event immunogenetics. Pediatric Infectious Disease Journal. 2009; 28(5): 431-432. PMid:19395950 http://dx.doi.org/10.1097/INF.0b013e3181a6a511

[33] Lam, P., Chambers, L., MacDougall, D.M.P., McCarthy, A.E. Seasonal influenza vaccination campaigns for health care personnel: A systematic review. Canadian Medical Association Journal. 2010; 182(12): e542-548. PMid:20643836 http://dx.doi.org/10.1503/cmaj.091304

[34] Flegel, K. Health care workersmust protect patients from influenza by taking the annual vaccine. Canadian Medical Association Journal 2012, 1. PMid:22007123 http://dx.doi.org/10.1503/cmaj.111480

[35] World Health Organization. WHO Global Infobase. Available from: https://apps.who.int/infobase/Comparisons.aspx (10 October 2012, date last accessed).

[36] Lippert, W. C., \& Wall, E. J. Optimal intramuscular needle-penetration depth. Pediatrics. 2008; 122(3): e556-563. PMid:18694903 http://dx.doi.org/10.1542/peds.2008-0374

[37] Ipp, M., Sam, J., \& Parkin, P.C. Needle aspiration and intramuscular vaccination. Archives of Pediatric Medicine. 2006; 160(4): 451. PMid:16585496 http://dx.doi.org/10.1001/archpedi.160.4.451-a

[38] Taddio, A., Appleton, M., Bortolussi, R., Chambers, C., Dubey, V., Halperin, S., et al. Reducing the pain of childhood vaccination: an evidence-based clinical practice guideline. Canadian Medical Association Journal. 2010; 182(18): E843-E855. PMid:21098062 http://dx.doi.org/10.1503/cmaj.101720

[39] Taddio, A., Ilersich, A.L., Ipp, M., Kikuta, A., Shah, V. Physical interventions and injection techniques for reducing injection pain during routine childhood immunizations: systematic review of randomized controlled trials and quasi-randomized control trials. Clinical Therapeutics. 2009; 31(Supplement B): S48-S76. PMid:19781436 http://dx.doi.org/10.1016/j.clinthera.2009.07.024

[40] Lee, D., Lee., S., \& Eldridge, K. A study of established nursing practice: An intramuscular injection technique. Journal of the Royal College of Nursing. 2005; 2: 32-36. http://dx.doi.org/10.1016/S1322-7696(08)60115-8

[41] Carter-Templeton, H., \& McCoy, T. Are we on the same page: A comparison of intramuscular injection explanations in nursing fundamental texts. Medsurg Nursing. 2008; 17: 237-240. PMid:18807857

[42] Wilkoff, W.G. Where's the point? Pediatric News. 2008; 14: 20. http://dx.doi.org/10.1016/S0031-398X(08)70589-7

[43] Alberta Health Services. Seasonal influenza immunization orientation workbook, 2011-2012. Edmonton, AB: Alberta Health Services, 2011.

[44] Cetik, O., Uslu, M., Ibrahim, A., Comert, A., Tekdemir, I., \& Cift, H. Is there a safe area for the axillary nerve in the deltoid muscle? Journal of Bone and Joint Surgery. 2006; 88-A: 2395-2399. PMid:17079396 http://dx.doi.org/10.2106/JBJS.E.01375

[45] Wynaden, D., Landsborough, I., McGowan, S., Baigmohamad, M.F., \& Pennebaker, D. Best practice guidelines for the administration of intramuscular injections in the mental health setting. International Journal of Mental Health Nursing. 2006; 15: 195-200. PMid:16916413 http://dx.doi.org/10.1111/j.1447-0349.2006.00423.x 